Genomics

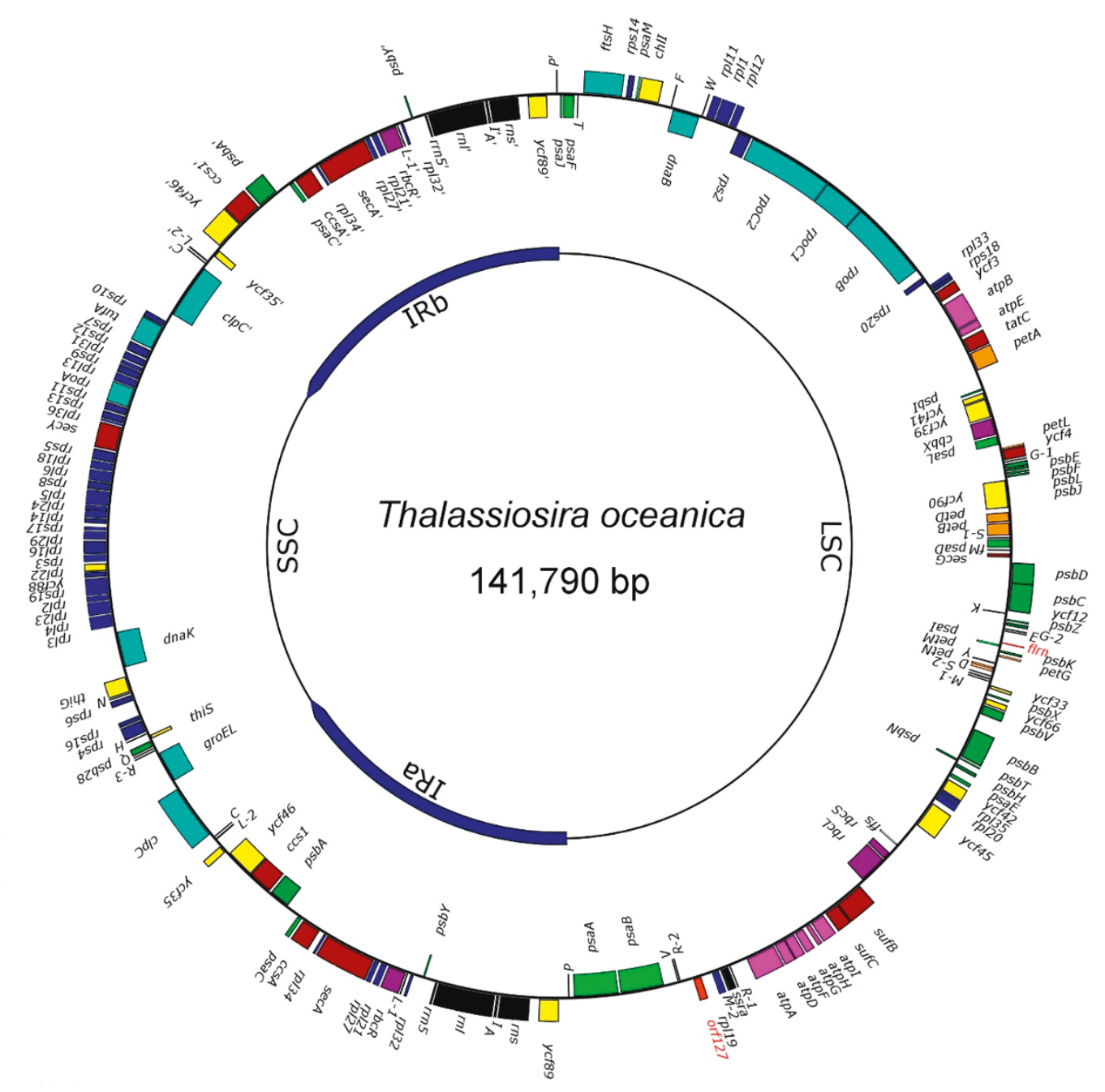

Recent transfer of an iron-regulated gene from the plastid to the nuclear genome in an oceanic diatom adapted to chronic iron limitation

Lommer et al. 


\title{
Recent transfer of an iron-regulated gene from the plastid to the nuclear genome in an oceanic diatom adapted to chronic iron limitation
}

\author{
Markus Lommer ${ }^{1}$, Alexandra-Sophie Roy ${ }^{1}$, Markus Schilhabel ${ }^{2}$, Stefan Schreiber ${ }^{2}$, Philip Rosenstiel ${ }^{2}$, Julie LaRoche ${ }^{1^{*}}$
}

\begin{abstract}
Background: Although the importance and widespread occurrence of iron limitation in the contemporary ocean is well documented, we still know relatively little about genetic adaptation of phytoplankton to these environments. Compared to its coastal relative Thalassiosira pseudonana, the oceanic diatom Thalassiosira oceanica is highly tolerant to iron limitation. The adaptation to low-iron conditions in T. oceanica has been attributed to a decrease in the photosynthetic components that are rich in iron. Genomic information on T. oceanica may shed light on the genetic basis of the physiological differences between the two species.

Results: The complete 141790 bp sequence of the T. oceanica chloroplast genome [GenBank: GU323224], assembled from massively parallel pyrosequencing (454) shotgun reads, revealed that the petF gene encoding for ferredoxin, which is localized in the chloroplast genome in T. pseudonana and other diatoms, has been transferred to the nucleus in T. oceanica. The iron-sulfur protein ferredoxin, a key element of the chloroplast electron transport chain, can be replaced by the iron-free flavodoxin under iron-limited growth conditions thereby contributing to a reduction in the cellular iron requirements. From a comparison to the genomic context of the T. pseudonana petF gene, the T. oceanica ortholog can be traced back to its chloroplast origin. The coding potential of the T. oceanica chloroplast genome is comparable to that of T. pseudonana and Phaeodactylum tricornutum, though a novel expressed ORF appears in the genomic region that has been subjected to rearrangements linked to the petF gene transfer event.

Conclusions: The transfer of the petF from the cp to the nuclear genome in T. oceanica represents a major difference between the two closely related species. The ability of $T$. oceanica to tolerate iron limitation suggests that the transfer of petF from the chloroplast to the nuclear genome might have contributed to the ecological success of this species.
\end{abstract}

\section{Background}

In contemporary oceans, diatoms account for approximately $40 \%$ of the oceanic primary production and play a critical role in the sequestration of atmospheric $\mathrm{CO}_{2}$ into the deep ocean [1]. The high diversity of diatoms and their cosmopolitan distribution in the marine environment reflect the ecological success endured by this group since their first appearance more than $150 \mathrm{Ma}$ ago [2].

Although diatoms thrive in coastal areas where dissolved nutrients are high, many species of diatoms are

\footnotetext{
* Correspondence: jlaroche@ifm-geomar.de

'Leibniz Institute of Marine Sciences at Kiel University IFM-GEOMAR, Kiel, Germany

Full list of author information is available at the end of the article
}

prevalent in high-nutrient, low-chlorophyll (HNLC) oceanic regions where primary production is chronically iron-limited [3]. Iron fertilization experiments in HNLC regions have repeatedly demonstrated the ability of opportunistic diatom species to bloom once iron is no longer growth limiting [4]. In contrast, some diatom species such as Thalassiosira oceanica thrive equally well in the presence or absence of iron [5]. A key determinant for the survival and growth of phytoplankton under iron limitation must be the ability to carry out photosynthesis efficiently, despite the high iron requirements of the photosynthetic infrastructure.

The photosynthetic apparatus, largely contained in the chloroplasts, is jointly coordinated by the plastid and

\section{Biomed Central}


nuclear genomes, involving more than 700 genes [6]. The chloroplast genome of most species generally retained less than 200 of the genes contributing to chloroplast function, as the majority of the endosymbiont's chloroplast genes have been lost or incorporated into the host nuclear genome. The plastids of diatoms and other chromalveolates, originated from a secondary endosymbiosis with a red alga, have retained a higher proportion of the symbiont's genes in their genomes relative to their green counterparts, which derived from a primary endosymbiosis with a cyanobacterium. The red origin of the chloroplasts [7] and the lower cellular iron requirements of the red lineage [8] may have contributed to the ecological success of diatoms in the marine environment in terms of a putative evolutionarybased pre-adjustment to iron-deplete conditions.

The retention of a core set of chloroplast genes and the factors preventing their transfer to the nucleus are the subject of ongoing debates [9]. The known chloroplast genomes of diatoms are circular with an extended inverted repeat region (IR) and are subject to internal rearrangements such as inversions [10]. Occasional organelle lysis and free release of organellar DNA is considered an important first step in the transfer of organelle-encoded genes to the nuclear genome. Indeed high quantities of chloroplast (cp) and mitochondrial (mt) DNA are frequently transferred and inserted into the nuclear genome, thereafter referred to as nuclear plastid or nuclear mitochondrial DNA (NUPTs, NUMTs) [11-14]. However, stable replacement of a plastid gene by its nuclear copy requires a retargeting of the nuclear gene product back to the chloroplast compartment as well as a functional expression and regulation. Until this multi-step development has been accomplished the chloroplast version cannot be discarded and the gene exists in two copies, which might even overlap in function in a differentially regulated manner [15]. Genes that provide a dual targeting sequence enabling import to both mitochondria and chloroplasts at the same time are also known [16].

Here, we present the complete T. oceanica CCMP1005 chloroplast genome sequence [GenBank: GU323224], which we assembled from a massively parallel pyrosequencing data set. Assembled genomic shotgun reads show that in the $T$. oceanica genome, the ferredoxin pet $F$ gene has been transferred to the nucleus. Ferredoxin is a photosynthetic redox protein that contains iron, and in diatoms it can be replaced by the iron-free flavodoxin, when iron-limited growth conditions prevail. The pet $F$ transfer to the nuclear genome may enable a refined regulation of this gene in response to iron availability in T. oceanica. Through comparative genomics between the coastal Thalassiosira pseudonana and the oceanic T. oceanica, we can trace the T. oceanica PETF gene back to its chloroplast origin and identify elements that may have played a role in the transfer of this important photosynthetic gene.

\section{Results}

Characteristics of the $T$. oceanica chloroplast genome

The cp genome of $T$. oceanica has a physical size of $141790 \mathrm{bp}$ and maps to a circular topology (Figure 1), slightly larger in size than the published cp genomes of the closely related $T$. pseudonana and the more distantly related $P$. tricornutum (Table 1). The cp genome of $P$. tricornutum shows a significantly higher $\mathrm{G}+\mathrm{C}$ content and contains three protein coding genes not present in the cp genomes of T. oceanica or T. pseudonana, while the $6.9 \mathrm{Kbp}$ inverted repeat region is significantly smaller than in the two Thalassiosira species. The gene composition of the large and small single copy regions (LSC, SSC) and inverted repeat subdomains (IRa, IRb) is nearly identical between T. oceanica and T. pseudonana. The differences in the overall size of their cp genomes can be solely attributed to the expansion of the inverted repeat region in $T$. oceanica leading to a de facto duplication of the three genes $\operatorname{clp} C, \operatorname{trn} C$ and $\operatorname{trn} L$, and to the loss of the petF gene from the large single copy region. Novel features of the $T$. oceanica cp genome are the appearance of an expressed orf 127 at the site affected by the petF gene transfer event, and the partial duplication of the RNA gene $f f s$ referred to as flrn (ffs-like RNA). Synteny between $T$. oceanica and T. pseudonana is weakly conserved (data not shown) and indicates a high degree of dynamic restructuring of chloroplast genomes mainly in form of small scale inversions, though restricted to the respective subdomains (LSC, SSC, IR) without crossing the borders of these elements (compare [10]).

\section{Transfer of petF gene to the nuclear genome in $T$. oceanica}

The ferredoxin petF gene is not present in the cp genome of $T$. oceanica indicating a loss or transfer of that gene to the nucleus. To address this question, BLAST analysis of 454 whole genome shotgun data was performed and revealed the presence of a nuclear genomic contig containing a complete PETF gene, confirming the gene transfer event. The nuclear genomic context of the PETF region could be assembled manually from the 454 sequence read data and was compared to the syntenic region of T. pseudonana (Figure 2). In the T. pseudonana cp genome, the petF gene is located between the genes rpl19 and psaB; the comparable site in T. oceanica shows the $T$. pseudonana petF gene being replaced by a sequence block consisting of the novel orf 127 and the tRNA genes $\operatorname{trn} V$ and $\operatorname{trn} R$. Interestingly, the latter unit is surrounded by an unusually large dispersed $74 \mathrm{bp}$ 


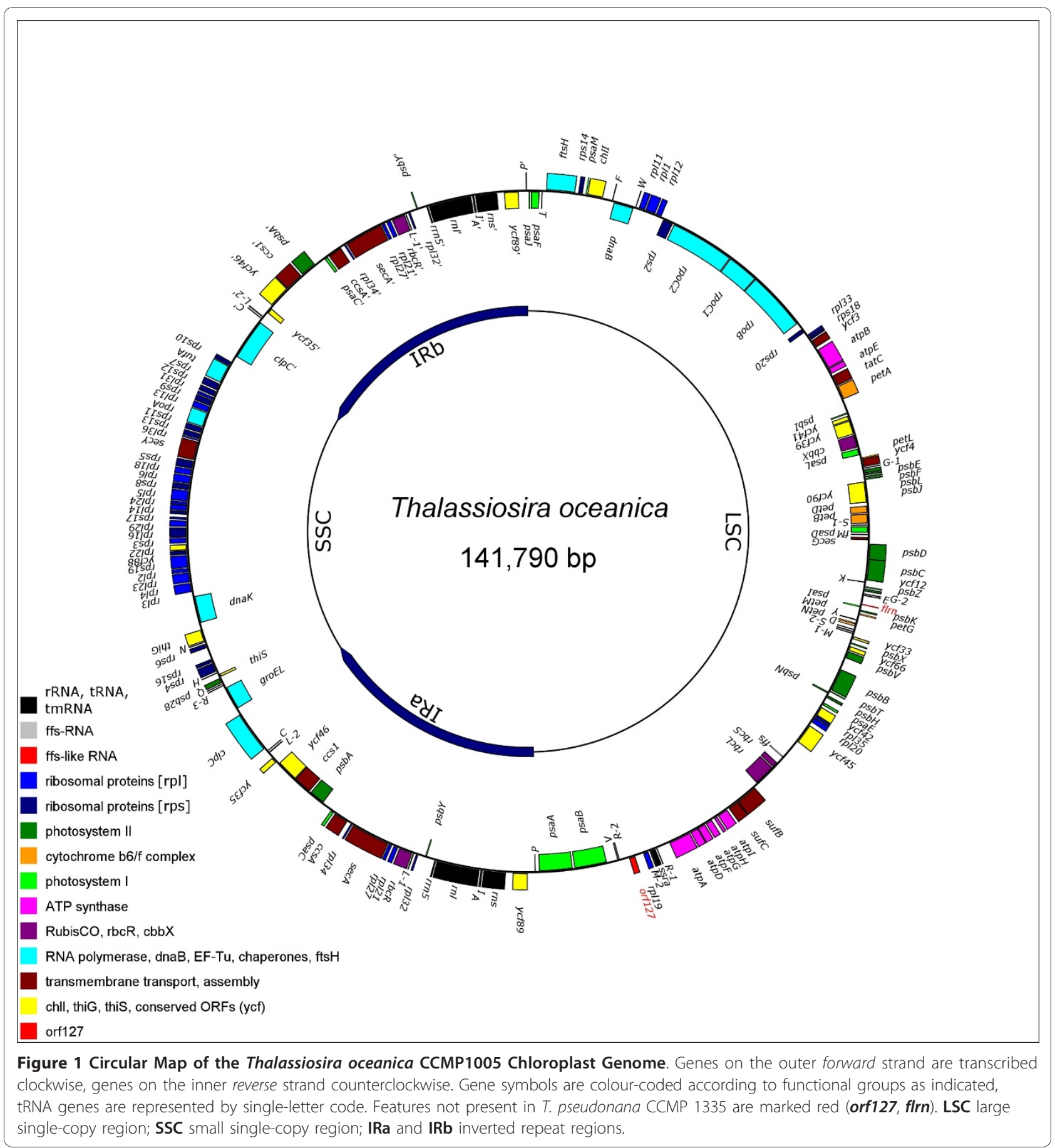

inverted repeat, indicating major genomic rearrangements in that region mediated by these elements and involving a recruitment of the two tRNA genes from a more distant site. Mapping of the PETF gene on the nuclear genomic fragment revealed a PETF gene model composed of two exons separated by an intron. The first exon encodes a chloroplast targeting peptide, while the second exon carries the information for the conserved functional part of the ferredoxin gene product. The predicted gene model reveals a nuclear promoter as well as a polyA-signal. The PETF gene and the adjacent $P D D$ gene encoding for a pyridoxal-dependent decarboxylase [17] are surrounded by larger non-related repeat elements ( $>1000 \mathrm{bp}$ ) likely representing remnants of recombinational genomic rearrangements involved in the pet $F$ gene transfer event. A highly conserved ortholog of the $P D D$ 
Table 1 Chloroplast Genome Features of $T$. oceanica in Comparison with $T$. pseudonana and $P$. tricornutum

\begin{tabular}{|c|c|c|c|}
\hline & $\begin{array}{r}\text { Thalassiosira oceanica CCMP } \\
1005\end{array}$ & $\begin{array}{r}\text { Thalassiosira pseudonana } \\
\text { CCMP } 1335\end{array}$ & $\begin{array}{r}\text { Phaeodactylum tricornutum CCAP } \\
1055 / 1\end{array}$ \\
\hline genome size [bp] & 141790 & 128814 & 117369 \\
\hline LSC & 70298 & 65250 & 63674 \\
\hline SSC & 24106 & 26889 & 39871 \\
\hline \multirow[t]{2}{*}{ IR } & 23693 & IRa: 18338 & 6912 \\
\hline & & IRb: 18337 & \\
\hline G+C content $[\%]$ & 30,39 & 30,66 & 32,56 \\
\hline A+T content $[\%]$ & 69,61 & 69,34 & 67,44 \\
\hline gene content [\#] & $158+2$ & 159 & 162 \\
\hline protein coding & $126+$ orf 127 & 127 & 130 \\
\hline rRNA & 3 & 3 & 3 \\
\hline tRNA & 27 & 27 & 27 \\
\hline other RNAs & $2+f / r n$ & 2 & 2 \\
\hline in $T$. oceanica, but not in T. pseudonana & orf127 ${ }^{\mathrm{a}}$, flrn & & \\
\hline in $T$. pseudonana, but not in T. oceanica & & pet $F^{a}$ & \\
\hline $\begin{array}{l}\text { in IR of } T \text {. oceanica, but not in IR of } T \text {. } \\
\text { pseudonana }\end{array}$ & clpC, trnC, trnL & & \\
\hline in $P$. tricornutum only & & & $t s f$, syfB, $a c p P$ \\
\hline
\end{tabular}

gene exists in T. pseudonana and its genomic context is shown as a virtual destination for the gene transfer in T. oceanica. The chloroplast's contribution to the newly formed nuclear PETF gene must at least be the conserved part of the petF ORF encoding for ferredoxin. Indeed the 5 ' and 3 ' borders of the conserved main coding region of the pet $F$ gene in the $T$. pseudonana chloroplast match comparable sequences in the nuclear PETF gene of $T$. oceanica (Figure 2 center). The situation at the 3 ' end illustrates that only a few changes are needed to transform parts of the AT-rich stem-loop terminating many chloroplast transcription units into a functional polyA-signal $\left(C_{2}\right)$ favouring termination of nuclear transcription. However, other conserved elements $\left(\mathrm{C}_{1}, \mathrm{C}_{3}\right)$ are maintained as well and support the chloroplast origin of a de novo nuclear polyA-signal. For functional transcription, the 5 ' end of the T. oceanica PETF exon 2 had to acquire a splice acceptor site linking it to the exon 1, encoding for the cp transit peptide. We observe that the T. pseudonana pet $F$ sequence contains motifs in its coding region that may act as a functional splice acceptor site (coloured bars) in a nuclear genomic context. In summary, the petF sequence as present in the T. pseudonana cp genome already contains several sequence motifs that would permit an incorporation of the petF gene as a nearly functional exon into a nuclear genomic context, thereby facilitating the modular acquisition of a second exon and promoter through further rearrangements.
An important step towards establishing a nuclear PETF gene is a functional retargeting of the ferredoxin gene product for import into the chloroplast and, hence, the acquisition of a chloroplast transit peptide. In T. oceanica this transit peptide is encoded as a functional unit by a separate exon, suggesting the presence of a donor gene encoding for another protein of plastid destination as a potential source for such a module by duplication and exon shuffling events. An alignment of the ferredoxin gene products, showing the exon structure of the T. oceanica PETF and LI818 (a gene encoding for a chlorophyll-binding light-harvesting protein) as such a possible donor gene for the transit peptide, is provided in Figure 3. The transit peptide in diatoms [18] has a length of approx. 28 aa and, while the T. oceanica PETF exon 2 encodes the highly conserved part of the protein, the part encoded by the 3 ' half of its exon 1 is less conserved and could have evolved from a sequence similar to the LI818 exon 1.

\section{Functional expression and differential regulation of PETF}

Ferredoxin contains iron and is often replaced by the ironfree flavodoxin in iron-limited growth conditions. Relative quantification studies using RT-qPCR confirm the functional expression of the transferred $T$. oceanica PETF gene. The down-regulation of PETF under iron-limited growth conditions was similar to that of $P C Y$, the gene encoding for plastocyanin, another photosynthetic protein involved in electron transfer (Figure 4). PETF and PCY show a 


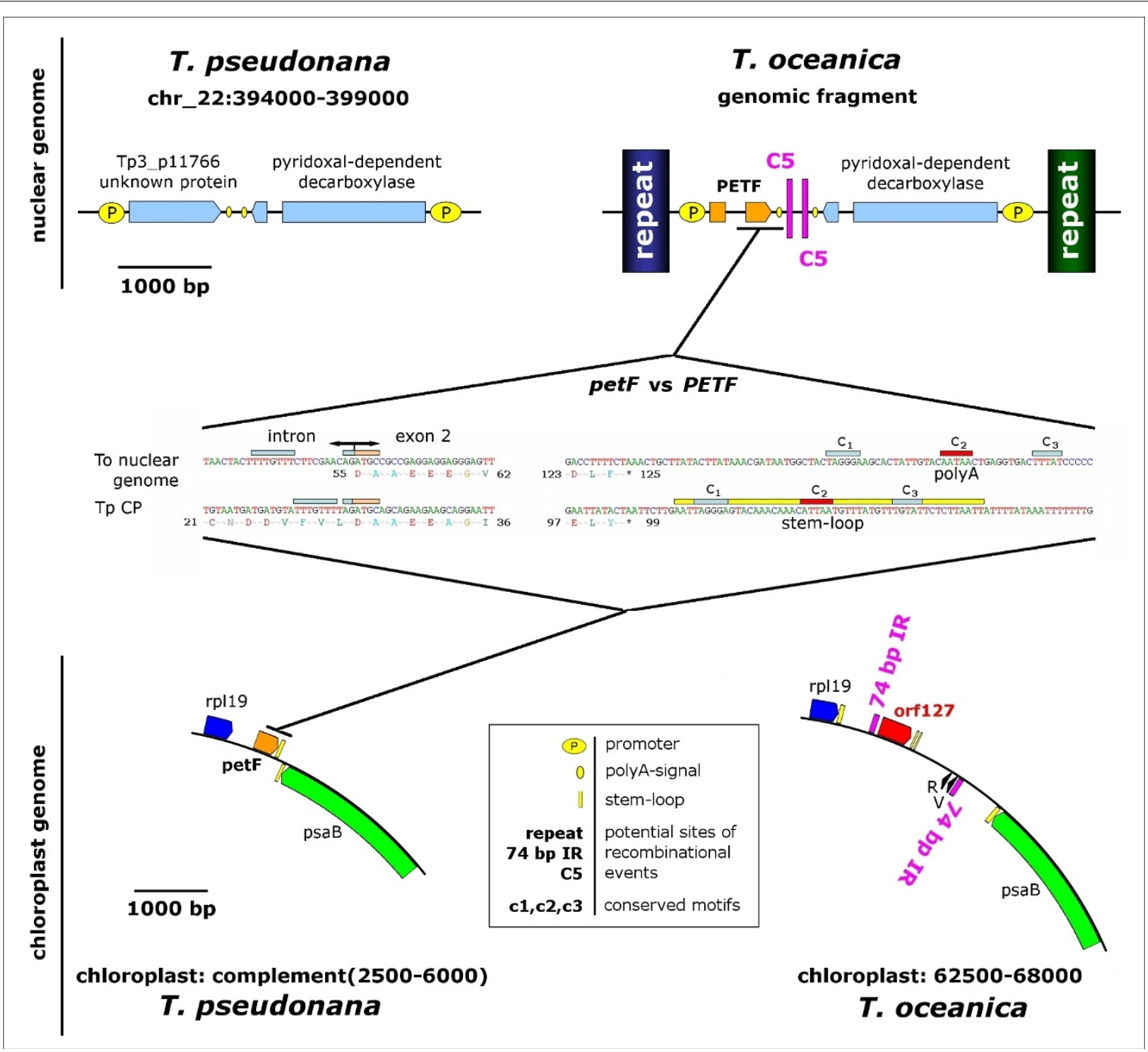

Figure 2 Genomic Context of the Thalassiosira petF Gene Transfer. The genomic context of the ferredoxin genes in T. oceanica and T. pseudonana indicates a recent gene transfer event. The T. pseudonana petF gene is part of the cp genome and is located between $r$ pl19 and psaB (bottom left), serving as a model for the genomic situation in a common ancestor of the two species. The T. oceanica PETF gene is found in the nuclear genome next to a PDD gene encoding for a pyridoxal-dependent decarboxylase (upper right) with a conserved ortholog present in T. pseudonana (upper left). The sites of excision (chloroplast) and insertion (nuclear fragment) in T. oceanica show major genome rearrangements in conjunction with the presence of a novel protein coding gene orf127 in the chloroplast. Both nuclear and chloroplast sites in T. oceanica contain various forms of repeat elements (,repeat", "74 bp IR") and motifs ("C5") that point to the recombinational events underlying the complex multi-step gene transfer (upper and bottom right); these are not present at the comparable sites in T. pseudonana. An alignment between the T. pseudonana and T. oceanica ferredoxin genes reveals sequence similarities at what might be the $5^{\prime}$ and $3^{\prime}$ ends of the transferred DNA segment (center). The T. pseudonana petF coding sequence already contains a potential functional splice acceptor site near the $\mathrm{N}$-terminus of the reading frame. A comparable situation in the ancestral T. oceanica cp genome would have facilitated the acquisition of an intron in a new genomic context leaving the major conserved part of the protein unaffected by the process (center left); the stem-loop (yellow bar), that serves as a transcriptional terminator for pet $\boldsymbol{F}$ in the $T$. pseudonana $\mathrm{cp}$ genome, contains motifs that are retained in the nuclear genomic context of T. oceanica PETF, one of them being slightly modified to become an eukaryotic polyA-signal (center right).

concerted down-regulation upon iron limitation as expected for constitutive photosynthesis genes, and in agreement with the observed down-regulation of photosynthesis in response to iron limitation. As expected, FLDA appears strongly up-regulated under iron-limited growth conditions, thereby supporting the idea of a mutual substitution of the ferredoxin and flavodoxin proteins.

\section{Novel features of the $T$. oceanica cp genome}

The genomic rearrangements in the $T$. oceanica cp genome accompanying the pet $F$ transfer led to a novel orf127 appearing at the inferred petF excision site. This gene encodes a protein of 140 aa containing two predicted transmembrane helices (Figure 5a) with no similarity to any known proteins in the NCBI nr database. 


Pt ferredoxin petF
Tp ferredoxin petF

The size and overall topology appear somewhat similar to the small transmembrane proteins from the FCP group of chlorophyll binding proteins, though sequence similarity or characteristic motifs are lacking. The gene is placed in a well-defined genomic context with an obvious ribosomal binding sequence GGGAGGG at -15

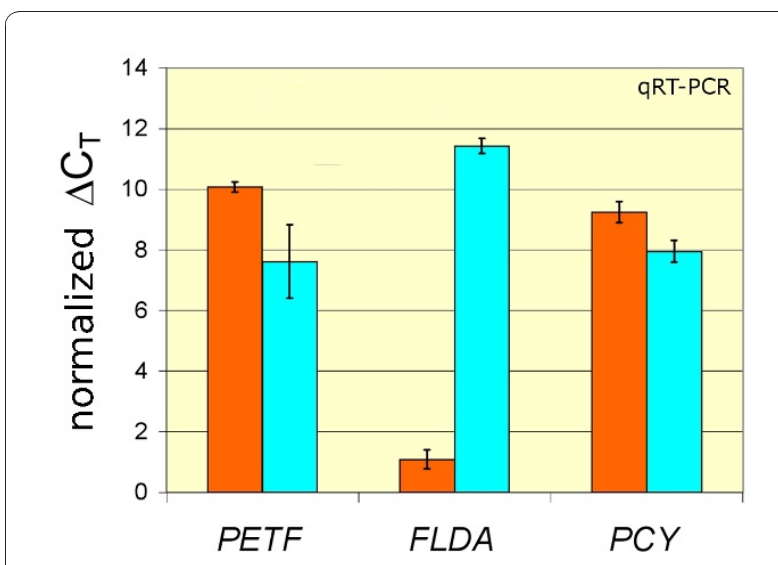

Figure 4 Functional Expression and Differential Regulation of PETF as a Function of Iron Level. Relative transcript abundances of the genes FLDA, PETF and PCY in triplicate iron-limited (light blue bars) and iron-replete cultures (orange bars) of $T$. oceanica were measured using a RT-qPCR approach with gene-specific primers pairs (Table 2). The normalized $\Delta C_{\mathbf{T}}$ values is calculated as $22-\Delta C_{T}$ where 22 is an arbitrary number chosen to provide a comparable positive logarithmic scale for the transcript abundance of the three genes tested, where a high normalized $\Delta \mathrm{C}_{\mathbf{T}}$ represents a high transcript level. and two small inverted repeats serving as a putative rho-independent transcriptional terminator.

As a second novel feature in the T. oceanica chloroplast genome we identified a duplication of the ffs RNA gene referred to as flrn. The ffs RNA adopts a stem-loop structure and is part of a signal recognition particle that might play a role at insertion of proteins into the inner chloroplast membrane [19]. An alignment of the flrn gene with the ffs genes of T. oceanica, T. pseudonana and $P$. tricornutum (Figure 5b) reveals that the flrn gene is truncated and contains a nucleotide polymorphism in the conserved loop region. Although the similarity between flrn and ffs is high, the truncated nature of flrn suggests that this sequence may represent a pseudogene.

\section{Discussion}

With new sequencing technologies emerging and an enormous increase of available sequence data, chloroplast genomes have drawn considerable interest not only for the purpose of phylogenetic reconstructions [20], but also for elucidating basic principles of genome organisation and dynamics of structural recombination events in comparative approaches [10]. Chloroplast genomes show a remarkable diversity among phototrophic eukaryotes [21]. However, their coding potential, ranging between 50 and 200 genes (Figure 6), is not even closely approaching the size and complexity of the plastid proteome needed to carry out the metabolic and physiological functions of the chloroplast. The plastid proteome is estimated to contain more than 700 proteins, many of uncertain structure and function [6]. Regulation of photosynthesis might even 


\section{Novel features in the}

\section{$T$. oceanica chloroplast genome}

\section{a) $\operatorname{orf} 127$}
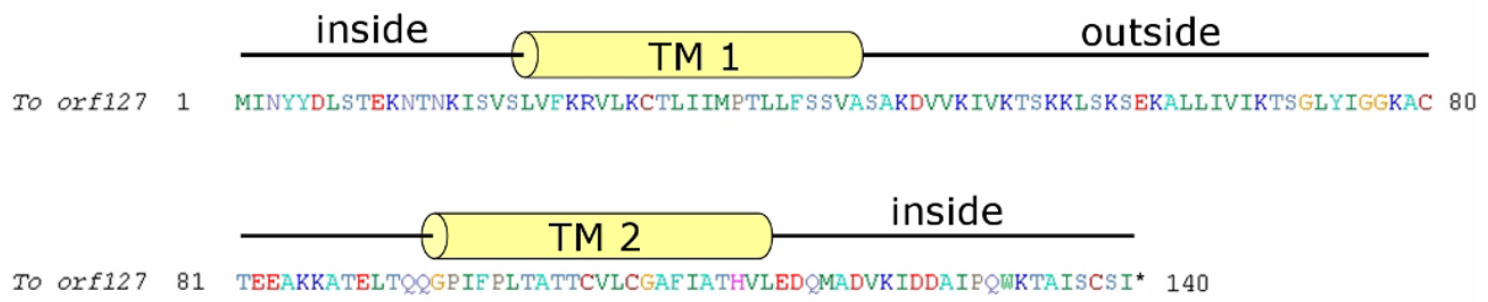

\section{b) flrn}
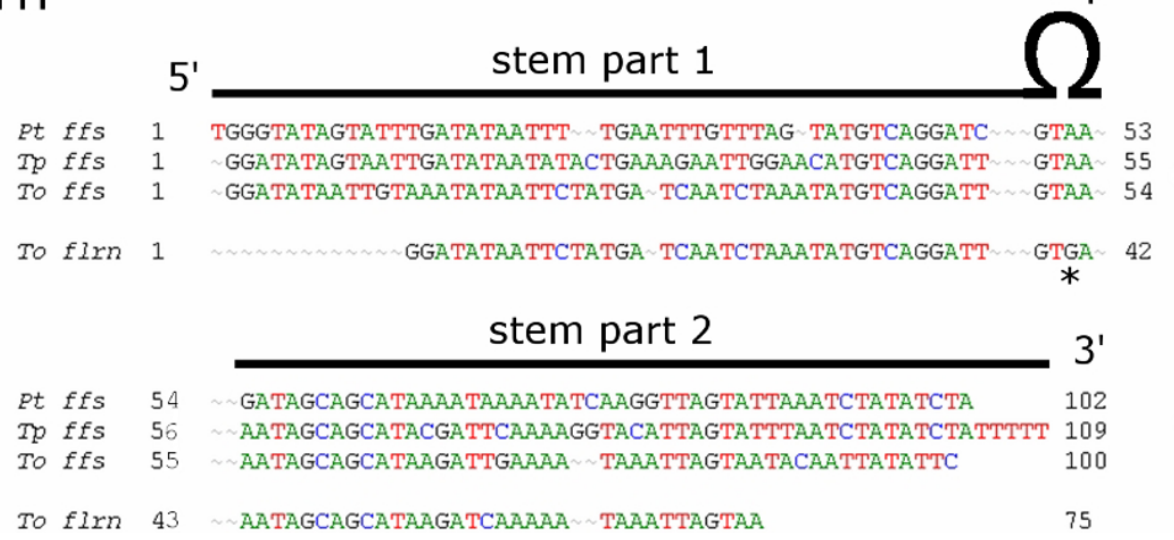

Figure 5 Novel Features in the $\boldsymbol{T}$. oceanica Chloroplast Genome. Two novel features of the $T$. oceanica $\mathrm{cp}$ genome are not found in $T$. pseudonana or other diatoms. The orf127 gene encodes a hypothetical transmembrane protein of 140 aa with no homology to any other proteins (a), the RNA gene flrn appears to have originated from a duplication of the conserved ffs gene that produces the RNA component of a particle involved in membrane insertion processes. An alignment of flrn to the ffs sequences from T. oceanica, T. pseudonana and $P$. tricornutum shows the high degree of conservation (b). EST evidence for both is weak, pointing to a potential pseudogene status, though orf127 shows a well-formed genomic structure with a strong RBS (GGGAGGG) and two stem-loops that might serve as a transcriptional terminator, while the flrn gene shows a remarkable conservation compared to its ffs counterpart with one of very few mismatches placed in the loop region $(*)$.

affect more than 4000 genes in Arabidopsis and novel proteins involved in elemental steps of photosynthesis are still being discovered [22].

The chloroplast genome is a dynamic structure in which the collinear binding of the inverted repeat regions likely leads to a handle-like structure isolating the LSC and SSC regions in separate domains and serving as a basis for occasional recombinational events that result in an inversion of the SSC region [23]. The weak conservation of synteny between T. oceanica and T. pseudonana cp genomes implies high structural dynamics of the circular genomic molecule, best explained by frequent inversion events. The remarkable lack of genomic rearrangements across the borders of the single copy regions, as observed by comparison between T. oceanica and T. pseudonana, could be explained by the structural separation of the LSC and SSC in a handle-like structure and supports this structural model.

The establishment of the primary endosymbiont as a chloroplast led to the loss of many of the endosymbiont's 


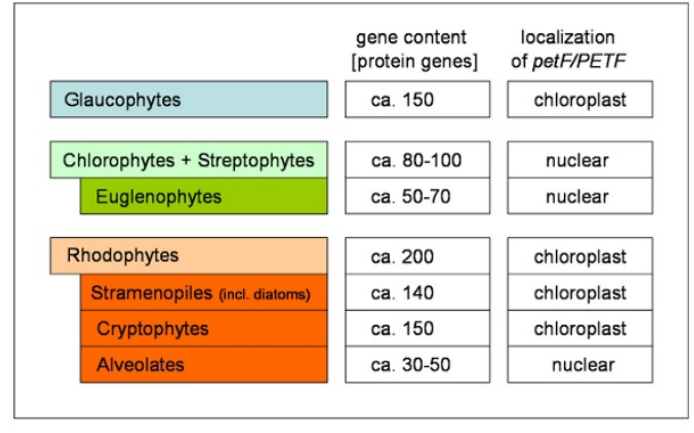

Figure 6 Subcellular Localization of the petF/PETF Gene in the Phylogenetic Context. A comparison of the chloroplast gene content between the main phylogenetic groups shows a reduced coding potential in the green line (Chlorophytes + Streptophytes, Euglenophytes) and in the Alveolates indicating extensive gene transfer to the nucleus or gene loss. The localization of the ferredoxin petF/PETF gene correlates with the extent of genome reduction, hence, $\boldsymbol{p e t} \boldsymbol{F}$ is generally retained in the larger $\mathrm{cp}$ genomes of Glaucophytes, Rhodophytes, Stramenopiles (incl. diatoms) and Cryptophytes. Protein gene numbers are taken from the Chloroplast Genome Database [54] and represent the majority of species in the respective groups, though exceptions can deviate from the given range. Phylogenetic groups originating from secondary endosymbiosis are indented.

genes or their transfer to the host's nucleus. Red algal and Glaucophyte chloroplasts retain about 200 protein coding genes, while most members of the green lineage exhibit a further genome reduction to less than 100 genes, indicating functional transfer of several essential genes to the nuclear genome. The substantial retention of coding potential in the primary plastids of the red algal lineage has been hypothesized to have an impact on the chloroplast portability during secondary endosymbiosis, preferentially facilitating further endosymbiotic events of autotrophs from the red lineage over their more reduced green counterparts [7]. Gene content of extant $\mathrm{cp}$ genomes derived from the red-algal lineage indicate that further gene loss or transfer proceeded after secondary endosymbiosis events, leading to a gene content of approx. 140 genes in the Stramenopiles and Cryptophytes. Stronger reductions can be found within the Apicomplexa and Dinophytes, referred to as Alveolates, perhaps because the known members of the Apicomplexa and several of the Dinophytes are non-photosynthetic organisms, and sometimes parasitic [24]. All of these subgroups are regarded as descendants of an ancient red algal endosymbiont and its host [7].

Occasional free release of cp genomic DNA upon chloroplast lysis is considered an important source of chloroplast DNA for integration into the nuclear genome. This mechanism can operate only in organisms containing multiple plastids. Indeed the higher degree of gene retention in P. tricornutum compared to Thalassiosira species might be partially explained by the presence of a single, unique chloroplast in P. tricornutum which would not be available for lysis in the context of the living cell. T. oceanica and T. pseudonana cells on the other hand are equipped with approx. 4 plastids each $[25,26]$.

As for other evolutionary processes, the transfer of chloroplast-encoded genes to the nuclear genome is difficult, if not impossible, to observe. Experimental approaches with transgenic tobacco have demonstrated that plastid genes can be successfully transferred to the nuclear genome [27], but most of the evidence for the inferred transfers is derived from phylogenetic and phylogenomic arguments [20]. Why certain genes are preferentially retained or transferred is puzzling and several theories have emerged ranging from a simple economic hypothesis in favour of gene transfer [28] to the CORR (CO-location for Redox Regulation) hypothesis in favour of gene retention [29]. The ferredoxin petF gene is not essentially retained in the $\mathrm{CP}$ genome, as a nuclear location is observed in several phylogenetic groups. So far, with the exception of $T$. oceanica, the petF gene has been retained in large cp genomes (Figure 6) such as the ones from red algae and descendants (including diatoms), and has generally been transferred to the nucleus in groups with reduced cp genomes such as Chlorophytes and Streptophytes. Several intrinsic features of the petF gene, conserved in the cp genomes of the closely related species $T$. pseudonana and $T$. weissflogii [30], may have facilitated the functional transfer of petF from the chloroplast to the nuclear genome in T. oceanica. Thus, in the coastal species T. pseudonana and $T$. weissflogii, the petF gene transfer may be waiting to happen as well, given appropriate environmental selection pressures. However, at this point, the establishment of the PETF gene in the nuclear genome of $T$. oceanica represents an exception within the diatoms for which genome information is available so far.

It has been demonstrated that the photosynthetic architecture in T. oceanica is better adapted to iron-limited areas than its coastal counterpart T. weissflogii [5]. Tolerance to iron limitation most likely arises from a combination of several genetic adaptations that contribute to a better streamlining of the photosynthetic apparatus towards low iron requirements. The low abundance of PSI relative to PSII in T. oceanica is clearly important in reducing the cellular iron requirements [5]. The substitution of the iron-requiring cytochrome $\mathrm{c}_{6}$ by the copper-containing plastocyanin in $T$. oceanica is an additional strategy to further reduce photosynthetic iron requirements, and, hence, the iron quota of this diatom [31]. Likewise, the flavodoxin 
expression is up-regulated upon iron limitation in many diatom species [32] while a simultaneous down-regulation of the expression of the ferredoxin petF gene is observed (e.g. [33]). In our study, we could confirm the expression and iron-dependent regulation of the ferredoxin PETF, the plastocyanin $P C Y$ and the flavodoxin FLDA gene in T. oceanica (Figure 4). The concerted down-regulation of PETF and $P C Y$ upon iron limitation is expected as part of the general down-regulation of the photosynthetic apparatus under iron limitation. In contrast, FLDA is strongly up-regulated in order to substitute ferredoxin with flavodoxin, consequently keeping intact the electron-transport interface between membrane-bound light reactions and dark reactions in the $\mathrm{cp}$ stroma.

The contrast in photosynthetic physiology between $T$. oceanica and its coastal relatives T. pseudonana and T. weissflogii make an attractive case to infer an adaptive significance for the transfer of petF, an iron-regulated cp gene, to the nuclear genome. Whether the transfer of pet $F$ to the nuclear genome is simply a byproduct of evolutionary trends towards chloroplast genome reduction or truly confers an ecological advantage with respect to the response to iron remains uncertain, though the observed high tolerance of $T$. oceanica to severe iron limitation relative to its close relatives $T$. pseudonana and T. weissflogii suggests that the latter hypothesis is worthy of further investigation.

Single gene transfers are the elemental steps of cp genome reduction and may confer benefits to single species in the context of niche adaptation. It is tempting to speculate that larger phylogenetic groups whose members share a reduced cp genome (as in the green lineage) likewise emerged from a founder species that profited from the benefits of $\mathrm{cp}$ genome reduction and improved nuclear control over organelle function. Centralized and synchronized regulation of $\mathrm{cp}$ metabolism is assumed to be a potential driving force for intracellular gene transfers. Organisms that already experienced large-scale cp genome reduction should benefit as well from an improved regulation of the transferred genes. The uniform genomic situation in larger phylogenetic groups raises the question whether such competitive advantages might even apply to these groups as a whole. A comparative evaluation of this effect between the red and green lineage is complicated by the interference with different extents of gene losses in both groups as well as the presence of distinct types of photosynthetic physiology in general. However, the terrestrial environment has been conquered exclusively by members of the green lineage, and prerequisite for this achievement might (at least partially) have been the improvement of regulatory capacities linked to cp genome reduction by large scale gene transfer. The settlement of the land represented the occupation of a new ecological niche rich in abiotic stresses of a novel type. It remains to be elucidated to which extent such specific environmental stresses exert a selective pressure favouring gene transfer events [34], ultimately leading to competitive advantage and enhanced fitness.

\section{Conclusions}

Although the chloroplast genomes of some closely related marine phytoplankton species have been sequenced, the differences between species within a genus have been small and restricted to gene reshuffling. Our findings, reporting a traceable single gene transfer from the chloroplast to the nuclear genome, are unique so far, in part because of the availability of both plastid and nuclear genome sequences for T. oceanica and T. pseudonana. The example of pet $F$ shows that chloroplast and nuclear genomes are of remarkable plasticity. Whether or not the gene transfer described for T. oceanica confers a competitive advantage still needs to be assessed through experimental approaches. Future analyses of cp genomes from a wider range of ecologically diverse species will likely reveal other surprising patterns of cp gene content, loss and regulation, and further enhance our understanding of their impacts on the evolutionary fitness of species.

\section{Methods}

\section{Strains and Cultures}

T. oceanica Hasle [25] strain CCMP1005 was grown from an axenic clonal isolate, obtained from serial dilutions of a stock culture to extinction. T. oceanica cells were grown in $8 \mathrm{l}$ batch cultures using iron-free $\mathrm{f} / 2$ nutrients [35] in ASW (artificial seawater medium [36]) supplied with $10 \mu \mathrm{M} \mathrm{FeCl}_{3}$ at $100 \mu \mathrm{E}, 25^{\circ} \mathrm{C}$ and a $14 / 10$ $\mathrm{h}$ light/dark cycle. Cells were harvested by filtration on $47 \mathrm{~mm} 5 \mu$-PC [polycarbonate]-filters, resuspended into a small volume of media, followed by centrifugation at $4^{\circ} \mathrm{C}$ for $10 \mathrm{~min}$ at $11000 \mathrm{rpm}$. Cell pellets were frozen in liquid $\mathrm{N}_{2}$ and stored at $-80^{\circ} \mathrm{C}$. Genome comparison was conducted with the genome data available at JGI and NCBI for T. pseudonana Hasle \& Heimdal CCMP1335 $[26,37]$ and Phaeodactylum tricornutum Bohlin CCAP1055/1 [38,39].

\section{Nucleic Acid Extraction and Sequencing}

Total genomic DNA for sequencing of the T. oceanica genome was extracted from nutrient-replete cells using the QIAGEN DNeasy kits. The quality of nucleic acids was assessed by NanoDrop UV absorption profiles and agarose gel electrophoresis. Next generation 454 sequencing technology [40] was applied to the gDNA as follows. After mechanical shearing, specific sequencing adaptors were ligated and the genomic DNA fragments were shotgun sequenced using massively parallel 
pyrosequencing on a 454 gs-flx instrument (Roche, Penzberg, Germany) according to the manufacturer's protocol. The resulting libraries were sequenced on a gs-flx sequencer using the standard manufacturer's protocol.

\section{Cp Genome Sequence Assembly and Gap Closure}

1.2 Mio flx pyrosequencing reads were assembled into contigs with the TGICL assembler using the CAP3 algorithm [41]. The quality of the resulting contigs was manually confirmed by inspection using the CLVIEW cluster viewer program. Using the local BLAST package from NCBI [42], we identified 9 contigs with high sequence coverage as elements of the cp genome. Additional information extracted from the contig ends of the ace-file of the original assembly, enabled the manual assembly of the cp genome to near completeness. The two remaining small gaps were targeted by PCR amplification of the contig ends and demonstrated physical continuity of the gap regions. Bridging fragments were cloned in a TOPO cloning vector and their sequences determined by Sanger sequencing.

\section{Sequence Analysis and Annotation}

The assembled chloroplast genome sequence was analyzed by BLAST against the related $T$. pseudonana $\mathrm{cp}$ genome sequence, the NCBI nr (non-redundant) protein database and the NCBI CDD Conserved Domain Database. The BLAST analysis revealed few obvious artificial frameshifts within the original contigs, allowing correction of the chloroplast scaffold for single nucleotide errors placed in low complexity regions of single nucleotide repeats that generally appear to be critical in 454 data. The final chloroplast scaffold was annotated using Artemis [43] and the submission software Sequin [44]. Inverted repeats at the 3' end of genes representing putative rho-independent transcriptional terminators $[45,46]$ were identified with the EINVERTED tool from the EMBOSS software package [47]. Ribosomal Binding Sites (RBS) were determined manually from similarity to the AGGAGGT consensus sequence [48] and close proximity to the respective translation start. The contig containing the nuclear ferredoxin gene PETF was assembled manually from raw genomic 454 reads using local BLAST, database sequence retrieval and BioEdit [49]. Gene modelling was done with the GENSCAN webserver [50] and confirmed by NCBI blastx against the nr protein database. The derived transcript encoded a protein with high homology to $T$. pseudonana and $P$. tricornutum petF protein orthologs.

\section{Circular Map Construction}

The circular genomic map was constructed from the primary embl-annotation file using CGVIEW [51] as follows:
The embl-file was converted into an xml-file with the perlscript cgview_xml_builder.pl, which is enclosed in the CGVIEW package; the xml-file containing the formatting details for the circular map was then customized manually by adding functional categorization and appropriate gene symbol shapes and dimensions. The circular map was constructed from the $x m l$-file as $p n g$-graphic, using the CGVIEW main function. Gene names were added using the open source graphics program GIMP [52].

\section{RT-qPCR data}

Based on the transcript sequences of the 18S-rDNA, PETF, FLDA and PCY genes derived from the assembly data, sets of primers were designed and optimized to detect gene specific amplicons of approx. $100 \mathrm{bp}$ with uniformly high amplification efficiency (>95\%, Table 2 ). A local BLASTN analysis of the primers against all sequences available for T. oceanica confirmed the specificity of the primers for their respective genes. cDNA template was prepared from $1 \mu \mathrm{g}$ RNA by reverse transcription using the QuantiTect Rev. Transcription Kit (QIAGEN), followed by digestion of residual DNA using the included gDNA wipeout reagents. The cDNA was diluted to $0.5 \mathrm{ng}^{-1} \mathrm{l}^{-1}$ and $2.5 \mathrm{ng}$ were used per qPCR reaction run on an ABI Prism 7000 (Applied Biosystems). Cycling conditions were $2 \mathrm{~min}$ at $50^{\circ} \mathrm{C}$ (once), 2 min at $95^{\circ} \mathrm{C}$ (once), and 40 cycles of $95^{\circ} \mathrm{C}$ for $0: 15 \mathrm{~min}$, followed by $0: 30 \mathrm{~min}$ at $60^{\circ} \mathrm{C}$. The qPCR mixtures contained $12.5 \mu \mathrm{l}$ SYBR qPCR SUPERMIX W/ROX (Invitrogen), $0.5 \mu \mathrm{l}$ of $10 \mu \mathrm{M}$ forward and reverse primer each, $6.5 \mu \mathrm{l} \mathrm{H}_{2} \mathrm{O}$ and $5 \mu \mathrm{l}$ of cDNA template. Gene expression was assessed as the mean from the $C_{T}$ values of 2-4 replicate reactions at a threshold level of 0.2 . Relative expression of genes with respect to the $18 \mathrm{~S}$ rDNA gene was calculated using the $\Delta C_{\mathrm{T}}$ method $\left(\Delta \mathrm{C}_{\mathrm{T}}\right.$ [geneX] $=\mathrm{C}_{\mathrm{T}}$ [gene $\left.\left.X\right]-\mathrm{C}_{\mathrm{T}}[18 \mathrm{~S}]\right)$. Final data are presented as the mean \pm s.e.m. of the $\Delta C_{T}$ values from three biological replicates.

\section{Nomenclature of Gene Names}

The nomenclature of gene names follows the recommendations for Chlamydomonas reinhardtii [53]. Gene names are typed in italic and uppercase for nuclear genes $(P E T F)$ or italic and lower case for organelle genes $(p e t F)$.

Table 2 Oligonucleotide Primers used for RT-qPCR Analyses

\begin{tabular}{cll}
\hline Gene & Forward Primer $\left(\mathbf{5}^{\prime} \rightarrow \mathbf{3}^{\prime}\right)$ & Reverse Primer $\left(\mathbf{5}^{\prime} \rightarrow \mathbf{3}^{\prime}\right)$ \\
\hline PETF & AGGCCACCTCCCTCGACTAC & GCGGCATCGACGATGAAG \\
\hline FLDA & CCGGCCTITCTACTCGACC & TTGACGTCTCCGATGTCCTC \\
\hline$P C Y$ & CTCCGCCCCTGCTTACG & TCCCTTGCAGACAGTGACCTT \\
\hline
\end{tabular}




\section{Acknowledgements}

We thank Prof. Stefan Rose-John (Department of Biochemistry, ChristianAlbrechts-Universität, Kiel, Germany) for advice in the isolation of nuclear genomic DNA from T. oceanica and the access to his laboratory and equipment. This work was supported in part by a DFG grant to JLR (RO2138/6-1) and by the DFG Cluster of Excellence Future Ocean (EXC 80). Prof. T. Bosch and Dr. Georg Hemmrich provided help with the initial $\mathrm{cp}$ contig assembly. We thank Tania Klüver for help with the laboratory experiment and culturing of the algae.

\section{Author details}

${ }^{1}$ Leibniz Institute of Marine Sciences at Kiel University IFM-GEOMAR, Kiel, Germany. ${ }^{2}$ Institute of Clinical Molecular Biology, Christian-AlbrechtsUniversity Kiel, Kiel, Germany.

\section{Authors' contributions}

$M L$ performed the gap closure cloning, the cp genome assembly and annotation, the analysis of the petF gene transfer, prepared the figures and wrote a major portion of the manuscript.

ASR cultured the algae, carried out the RT-qPCR work and commented on the manuscript.

MS prepared the gDNA libraries and performed the 454 sequencing.

SS provided the sequencing technology and supply.

PR coordinated the sequencing and contributed to manuscript writing. JLR coordinated the study, isolated the T. oceanica gDNA, and made major contributions to discussion and manuscript writing

All authors read and approved the final manuscript.

Received: 1 June 2010 Accepted: 20 December 2010

Published: 20 December 2010

\section{References}

1. Dugdale RC, Wilkerson FP: Silicate regulation of new production in the equatorial Pacific upwelling. Nature 1998, 391:270-273

2. Finkel ZV, Katz ME, Wright JD, Schofield OME, Falkowski PG: Climatically driven macroevolutionary patterns in the size of marine diatoms over the cenozoic. Proc Natl Acad Sci USA 2005, 102:8927-8932.

3. Martin JH, Coale KH, Johnson KS, Fitzwater SE, Gordon RM, Tanner SJ, Hunter CN, Elrod VA, Nowicki JL, Coley TL, Barber RT, Lindley S, Watson AJ, Van Scoy K, Law CS, Liddicoat MI, Ling R, Stanton T, Stockel J, Collins C, Anderson A, Bidigare R, Ondrusek M, Latasa M, Millero FJ, Lee K, Yao W, Zhang JZ, Friederich G, Sakamoto C, Chavez F, Buck K, Kolber Z, Greene R, Falkowski P, Chisholm SW, Hoge F, Swift R, Yungel J, Turner S, Nightingale $P$, Hatton A, Liss P, Tindale NW: Testing the Iron Hypothesis in Ecosystems of the Equatorial Pacific-Ocean. Nature 1994, 371:123-129.

4. Boyd PW, Jickells T, Law CS, Blain S, Boyle EA, Buesseler KO, Coale KH, Cullen JJ, de Baar HJ, Follows M, Harvey M, Lancelot C, Levasseur M, Owens NP, Pollard R, Rivkin RB, Sarmiento J, Schoemann V, Smetacek V, Takeda S, Tsuda A, Turner S, Watson AJ: Mesoscale iron enrichment experiments 1993-2005: Synthesis and future directions. Science 2007 315:612-617.

5. Strzepek RF, Harrison PJ: Photosynthetic architecture differs in coastal and oceanic diatoms. Nature 2004, 431:689-692.

6. Kleffmann T, Russenberger D, von Zychlinski A, Christopher W, Sjolander K Gruissem W, Baginsky S: The Arabidopsis thaliana chloroplast proteome reveals pathway abundance and novel protein functions. Curr Biol 2004, 14:354-362.

7. Falkowski PG, Katz ME, Knoll AH, Quigg A, Raven JA, Schofield O, Taylor FJR: The evolution of modern eukaryotic phytoplankton. Science 2004, 305:354-360

8. Quigg A, Finkel ZV, Irwin AJ, Rosenthal Y, Ho TY, Reinfelder JR, Schofield O, Morel FMM, Falkowski PG: The evolutionary inheritance of elemental stoichiometry in marine phytoplankton. Nature 2003, 425:291-294.

9. Timmis JN, Ayliffe MA, Huang CY, Martin W: Endosymbiotic gene transfer: Organelle genomes forge eukaryotic chromosomes. Nat Rev Genet 2004, 5(2):123-135.

10. Oudot-Le Secq M-P, Grimwood J, Shapiro H, Armbrust EV, Bowler C, Green BR: Chloroplast genomes of the diatoms Phaeodactylum tricornutum and Thalassiosira pseudonana: comparison with other plastid genomes of the red lineage. Mol Genet Genomics 2007 277:427-439.
11. Martin W: Gene transfer from organelles to the nucleus: Frequent and in big chunks. Proc Natl Acad Sci USA 2003, 100:8612-8614.

12. Richly $E$, Leister D: NUPTs in sequenced eukaryotes and their genomic organization in relation to NUMTs. Mol Biol Evol 2004, 21:1972-1980.

13. Bock $R$, Timmis $J N$ : Reconstructing evolution: gene transfer from plastids to the nucleus. BioEssays 2008, 30:556-566.

14. Sheppard AE, Timmis JN: Instability of Plastid DNA in the Nuclear Genome. PLOS Genet 2009, 5:e1000323.

15. Fujita K, Ehira S, Tanaka K, Asai K, Ohta N: Molecular phylogeny and evolution of the plastid and nuclear encoded cbbX genes in the unicellular red alga Cyanidioschyzon merolae. Genes Genet Syst 2008, 83:127-133.

16. Ueda M, Nishikawa T, Fujimoto M, Takanashi H, Arimura S, Tsutsumi N, Kadowaki K: Substitution of the gene for chloroplast RPS16 was assisted by generation of a dual targeting signal. Mol Biol Evol 2008, 25:1566-1575.

17. Jackson FR: Prokaryotic and Eukaryotic Pyridoxal-Dependent Decarboxylases Are Homologous. J Mol Evol 1990, 31:325-329.

18. Kilian $\mathrm{O}$, Kroth $\mathrm{PG}$ : Identification and characterization of a new conserved motif within the presequence of proteins targeted into complex diatom plastids. Plant J 2005, 41:175-183.

19. Ulbrandt ND, Newitt JA, Bernstein HD: The E-coli signal recognition particle is required for the insertion of a subset of inner membrane proteins. Cell 1997, 88:187-196.

20. Moustafa A, Beszteri B, Maier UG, Bowler C, Valentin K, Bhattacharya D: Genomic Footprints of a Cryptic Plastid Endosymbiosis in Diatoms. Science 2009, 324:1724-1726.

21. Simpson $\mathrm{CL}$, Stern $\mathrm{DB}$ : The treasure trove of algal chloroplast genomes. Surprises in architecture and gene content, and their functional implications. Plant Physiol 2002, 129:957-966.

22. Eberhard S, Finazzi G, Wollman F-A: The Dynamics of Photosynthesis. Annu Rev Genet 2008, 42:463-515.

23. Cattolico RA, Jacobs MA, Zhou Y, Chang J, Duplessis M, Lybrand T, McKay J, Ong HC, Sims E, Rocap G: Chloroplast genome sequencing analysis of Heterosigma akashiwo CCMP452 (West Atlantic) and NIES293 (West Pacific) strains. BMC Genomics 2008, 9:211

24. Hackett JD, Anderson DM, Erdner DL, Bhattacharya D: Dinoflagellates: A remarkable evolutionary experiment. Am J Bot 2004, 91:1523-1534

25. Hasle GR: The Marine, Planktonic Diatoms Thalassiosira-Oceanica Sp-Nov and Thalassiosira-Partheneia. J Phycol 1983, 19:220-229.

26. Hasle GR, Heimdal BR: Some species of the centric diatom genus Thalassiosira studied in the light and electron microscopes. Beih zur Nova Hedwigia 1970, 31:543-581.

27. Huang CY, Ayliffe MA, Timmis JN: Direct measurement of the transfer rate of chloroplast DNA into the nucleus. Nature 2003, 422:72-76

28. Douglas $A E$, Raven JA: Genomes at the interface between bacteria and organelles. Philos Trans R Soc B 2003, 358:5-17.

29. Allen JF, Puthiyaveetil S, Ström J, Allen CA: Energy transduction anchors genes in organelles. BioEssays 2005, 27:426-435.

30. Gueneau P, Morel F, LaRoche J, Erdner D: The petF region of the chloroplast genome from the diatom Thalassiosira weissflogii: sequence, organization and phylogeny. Eur J Phycol 1998, 33:203-211.

31. Peers G, Price NM: Copper-containing plastocyanin used for electron transport by an oceanic diatom. Nature 2006, 441:341-344.

32. LaRoche J, Murray H, Orellana M, Newton J: Flavodoxin Expression as an Indicator of Iron Limitation in Marine Diatoms. J Phycol 1995, 31:520-530.

33. Allen AE, LaRoche J, Maheswari U, Lommer M, Schauer N, Lopez PJ, Finazzi G, Fernie AR, Bowler C: Whole-cell response of the pennate diatom Phaeodactylum tricornutum to iron starvation. Proc Natl Acad Sci USA 2008, 105:10438-10443.

34. Cullis CA, Vorster BJ, Van Der Vyver C, Kunert KJ: Transfer of genetic material between the chloroplast and nucleus: how is it related to stress in plants? Ann Bot 2009, 103:625-633.

35. Guillard RRL, Ryther JH: Studies of marine planktonic diatoms. I. Cyclotella nana Hustedt and Detonula confervacea Cleve. Can J Microbiol 1962, 8:229-239.

36. Goldman JC, McCarthy JJ: Steady-State Growth and Ammonium Uptake of a Fast-Growing Marine Diatom. Limnol Oceanogr 1978, 23:695-703.

37. Armbrust EV, Berges JA, Bowler C, Green BR, Martinez D, Putnam NH, Zhou SG, Allen AE, Apt KE, Bechner M, Brzezinski MA, Chaal BK, Chiovitti A, Davis AK, Demarest MS, Detter JC, Glavina T, Goodstein D, Hadi MZ, Hellsten U, Hildebrand M, Jenkins BD, Jurka J, Kapitonov W, Kroger N, 
Lau WWY, Lane TW, Larimer FW, Lippmeier JC, Lucas S, Medina M, Montsant A, Obornik M, Parker MS, Palenik B, Pazour GJ, Richardson PM, Rynearson TA, Saito MA, Schwartz DC, Thamatrakoln K, Valentin K, Vardi A, Wilkerson FP, Rokhsar DS: The genome of the diatom Thalassiosira pseudonana: Ecology, evolution, and metabolism. Science 2004, 306:79-86

38. Bohlin K: Zur Morphologie und Biologie einzelliger Algen. Öfvers of K Vet Acad Förhandl Stockholm 1897, 54:519-522.

39. Bowler C, Allen AE, Badger JH, Grimwood J, Jabbari K, Kuo A, Maheswari U, Martens C, Maumus F, Otillar RP, Rayko E, Salamov A, Vandepoele K, Beszteri B, Gruber A, Heijde M, Katinka M, Mock T, Valentin K, Verret F, Berges JA, Brownlee C, Cadoret JP, Chiovitti A, Choi CJ, Coesel S, De Martino A, Detter JC, Durkin C, Falciatore A, Fournet J, Haruta M, Huysman MJ, Jenkins BD, Jiroutova K, Jorgensen RE, Joubert $Y$, Kaplan A Kröger N, Kroth PG, La Roche J, Lindquist E, Lommer M, Martin-Jézéquel V, Lopez PJ, Lucas S, Mangogna M, McGinnis K, Medlin LK, Montsant A, Oudot-Le Secq MP, Napoli C, Obornik M, Parker MS, Petit JL, Porcel BM, Poulsen N, Robison M, Rychlewski L, Rynearson TA, Schmutz J, Shapiro H, Siaut M, Stanley M, Sussman MR, Taylor AR, Vardi A, von Dassow P, Vyverman W, Willis A, Wyrwicz LS, Rokhsar DS, Weissenbach J, Armbrust EV, Green BR, Van de Peer Y, Grigoriev IV: The Phaeodactylum genome reveals the evolutionary history of diatom genomes. Nature 2008 , 456:239-244.

40. Wolff J, Bayer T, Haubold B, Schilhabel M, Rosenstiel P, Tautz D: Nucleotide divergence versus gene expression differentiation: 454 transcriptome sequencing in natural isolates from the carrion crow and its hybrid zone with the hooded crow. Mol Ecol 2010, 19(Suppl 1):162-75.

41. Pertea G, Huang XQ, Liang F, Antonescu V, Sultana R, Karamycheva S, Lee Y, White J, Cheung F, Parvizi B, Tsai J, Quackenbush J: TIGR Gene Indices clustering tools (TGICL): a software system for fast clustering of large EST datasets. Bioinformatics 2003, 19:651-652.

42. Altschul SF, Gish W, Miller W, Myers EW, Lipman DJ: Basic Local Alignment Search Tool. J Mol Biol 1990, 215:403-410.

43. Rutherford K, Parkhill J, Crook J, Horsnell T, Rice P, Rajandream MA, Barrell B. Artemis: sequence visualization and annotation. Bioinformatics 2000 16:944-945.

44. Benson DA, Karsch-Mizrachi I, Lipman DJ, Ostell J, Wheeler DL: GenBank. Nucleic Acids Res 2006, 34:D16-D20

45. Farnham PJ, Platt T: Rho-Independent Termination - Dyad Symmetry in DNA Causes Rna-Polymerase to Pause During Transcription Invitro. Nucleic Acids Res 1981, 9:563-577.

46. Wilson KS, Von Hippel PH: Transcription Termination at Intrinsic Terminators - the Role of the RNA Hairpin. Proc Natl Acad Sci USA 1995, 92:8793-8797.

47. Rice P, Longden I, Bleasby A: EMBOSS: The European molecular biology open software suite. Trends Genet 2000, 16:276-277.

48. Shine J, Dalgarno L: Determinant of Cistron Specificity in Bacterial Ribosomes. Nature 1975, 254:34-38.

49. Hall TA: BioEdit: a user-friendly biological sequence alignment editor and analysis program for Windows 95/98/NT. Nucleic Acids Symp Ser 1999, 41:95-98.

50. The GENSCAN Web Server at MIT. [http://genes.mit.edu/GENSCAN.html].

51. Stothard P, Wishart DS: Circular genome visualization and exploration using CGView. Bioinformatics 2005, 21:537-539.

52. GNU Image Manipulation Program. [http://www.gimp.org/].

53. Chlamy Center - An Online Informatics Resource for Chlamydomonas. [http://www.chlamy.org/nomenclature.html].

54. Cui L, Veeraraghavan N, Richter A, Wall K, Jansen RK, Leebens-Mack J, Makalowska I, dePamphilis CW: ChloroplastDB: the chloroplast genome database. Nucleic Acids Res 2006, 34:D692-D696.

doi:10.1186/1471-2164-11-718

Cite this article as: Lommer et al:: Recent transfer of an iron-regulated gene from the plastid to the nuclear genome in an oceanic diatom adapted to chronic iron limitation. BMC Genomics 2010 11:718.

\section{Submit your next manuscript to BioMed Central and take full advantage of:}

- Convenient online submission

- Thorough peer review

- No space constraints or color figure charges

- Immediate publication on acceptance

- Inclusion in PubMed, CAS, Scopus and Google Scholar

- Research which is freely available for redistribution

Submit your manuscript at www.biomedcentral.com/submit 